\title{
TU/e EmonONEN

\section{An inductive down converter system-in-package for integrated power management in battery-powered applications}

\section{Citation for published version (APA):}

Bergveld, H. J., Karadi, R., \& Nowak, K. (2008). An inductive down converter system-in-package for integrated power management in battery-powered applications. In Proc. IEEE Power Electronics Specialist Conference (PESC 2008, Rhodes, 15-19 June 2008) (pp. 3335-3341). Institute of Electrical and Electronics Engineers. https://doi.org/10.1109/PESC.2008.4592470

DOI:

10.1109/PESC.2008.4592470

Document status and date:

Published: 01/01/2008

\section{Document Version:}

Publisher's PDF, also known as Version of Record (includes final page, issue and volume numbers)

\section{Please check the document version of this publication:}

- A submitted manuscript is the version of the article upon submission and before peer-review. There can be important differences between the submitted version and the official published version of record. People interested in the research are advised to contact the author for the final version of the publication, or visit the $\mathrm{DOI}$ to the publisher's website.

- The final author version and the galley proof are versions of the publication after peer review.

- The final published version features the final layout of the paper including the volume, issue and page numbers.

Link to publication

\section{General rights}

Copyright and moral rights for the publications made accessible in the public portal are retained by the authors and/or other copyright owners and it is a condition of accessing publications that users recognise and abide by the legal requirements associated with these rights.

- Users may download and print one copy of any publication from the public portal for the purpose of private study or research.

- You may not further distribute the material or use it for any profit-making activity or commercial gain

- You may freely distribute the URL identifying the publication in the public portal.

If the publication is distributed under the terms of Article 25fa of the Dutch Copyright Act, indicated by the "Taverne" license above, please follow below link for the End User Agreement:

www.tue.nl/taverne

Take down policy

If you believe that this document breaches copyright please contact us at:

openaccess@tue.nl

providing details and we will investigate your claim. 


\title{
An Inductive Down Converter System-in- Package for Integrated Power Management in Battery-powered Applications
}

\author{
H.J. Bergveld, R. Karadi and K. Nowak \\ NXP Semiconductors, Corporate Innovation \& Technology, Research, Department Mixed-Signal Circuits and Systems, \\ High Tech Campus 37, 5656 AE, Eindhoven, the Netherlands, HenkJan.Bergveld@nxp.com
}

\begin{abstract}
With the increasing number of voltage conversions that have to be efficiently implemented in a mobile device, the PCB space occupied by switched-mode DC-DC converters with external passive components will become unacceptably high. Therefore, a clear need exists for small-form-factor high-efficiency DC-DC converters having the necessary passive components integrated within one package. This will enable the integration of a DC-DC converter with the load and consequently the system integration of power management. This paper describes the measurement results of an integrated inductive down converter, where the active electronics (power stage and driver circuitry) has been implemented in 0.18- $\mu \mathrm{m}$ CMOS technology and the passive components (output LC filter and decoupling capacitor) have been implemented in a stateof-the-art proprietary passive-integration process technology using high-density trench-MOS capacitors (80 $\mathrm{nF} / \mathrm{mm}^{2}$ ) and an 8- $\mu \mathrm{m}$ thick copper top metallization layer. The active die of the converter has been flip-chipped on top of the passive die to reduce parasitic component values. This yields a System-in-Package (SiP) that achieves a step-down DC-DC conversion without any external components. Due to the limited inductance achievable with the used planar air coil in the acceptable area, the switching frequency of the DC-DC converter has been increased. At the same time, Zero-Voltage-Switching (ZVS) measures have been implemented to reduce the switching losses at this increased frequency. A maximum efficiency of $65 \%$ at $80 \mathrm{MHz}$ has been achieved for an input voltage of $1.8 \mathrm{~V}$, an output voltage of $1.1 \mathrm{~V}$ and an output current of $100 \mathrm{~mA}$. After explaining the motivation behind integrated power management and the choice for an integrated inductive converter, this paper describes the main design aspects of the realized integrated inductive DC-DC down converter. Next, it presents some details of the used passive-integration process, the design of the passive die including the LC filter and the construction of the SiP. Finally, the measurement results of the converter are discussed and conclusions are drawn.
\end{abstract}

\section{INTRODUCTION}

The number of features implemented in mobile devices increases dramatically leading to a multitude of different supply voltages, all of which need to be generated from a single battery voltage. For example, the current invasion of solid-state lighting applications, such as LED flash allowing improved photo quality, leads to different voltage and current requirements than other applications and therefore necessitates the addition of DC/DC converters to the system. At the same time, the continuous drive towards better autonomy has led to the use of voltage islands in digital ICs. In each voltage island the lowest possible supply voltage is used to run the connected digital circuitry at the optimum efficiency. This is commonly referred to as voltage scaling and leads to even more different supply voltages that need to be independently generated from the battery voltage [1].

For optimum efficiency, especially larger voltage differences need to be converted by switched-mode DCDC converters, including capacitive and inductive DC/DC converters. Linear regulators yield unacceptably low efficiencies in this case. Capacitive converters have the advantage of not needing an inductor, which is often costly and bulky, but the control of the output voltage over input-voltage variations is limited since the voltageconversion ratio is determined by the circuit topology. A possible solution to this problem is to vary the effective output resistance of the converter, e.g. by changing the duty cycle at which the switches are addressed, but this substantially decreases efficiency when the input-voltage range is relatively large [2]. For a large input-voltage range, which appears in all targeted mobile applications using a Li-ion battery, the alternative solution to maintain output-voltage regulation and acceptable efficiency is to implement multi-ratio capacitive converters where the appropriate ratio is chosen dependent on the input voltage and load requirements [3],[4]. However, in order to optimize the average efficiency over the input-voltage range the number of ratios may become rather high, leading to a relatively large number of capacitors.

Inductive DC-DC converters are attractive, since they enable good control of the output voltage over inputvoltage and output-load variations by means of controlling the duty cycle of the power switches using only three passive components. Two capacitors are used for input decoupling and output filtering, respectively, and one inductor is used for energy transfer from input to output.

Both in the case of capacitive and inductive DC-DC converters, however, using external passive components to accommodate the increasing number of voltage conversions would lead to unacceptably high volume and cost. Therefore, the need arises for small-form-factor highly efficient DC-DC converters with packageintegrated passive components. This enables integration of the DC-DC converter with the load, and, consequently, the system integration of power management. As mentioned above, inductive DC-DC converters are better able to 
handle the relatively large input-voltage range in Li-ionbattery-powered applications with a relatively low number of passive components. Since the voltage of the commonly used Li-ion battery is typically larger than the supply voltages for the ICs in a mobile device, this paper therefore focuses on integrated inductive down converters.

Air-core inductors are popular for realizing integrated inductors due to their relatively simple structure and good integration possibilities [5]-[8]. Since the required small volume and the low permeability of air limit the achievable inductance value, the switching frequency of the DC-DC converters has to be increased correspondingly, leading to low efficiencies without proper measures. The use of multiple air-core inductors in multi-phase Voltage-Regulator Module (VRM) applications has shown that efficiencies between $72 \%$ and $84 \%$ are possible for switching frequencies of $480 \mathrm{MHz}$ and $100 \mathrm{MHz}$, respectively, for output powers above $10 \mathrm{~W}$ [5],[6]. However, for mobile applications the required output powers are much lower, complexity should be low and the height of SMD inductors inside the package is unacceptable. A reported two-phase interleaved buck converter achieves 64\% efficiency for output powers between $300 \mathrm{~mW}$ and $400 \mathrm{~mW}$ at $65 \mathrm{MHz}$ switching frequency, but a $0.18-\mu \mathrm{m}$ SiGe process was used with an additional top copper metallization. This is unpractical for the integration with nm-CMOS circuits [7]. Similarly, a single-stage buck converter realized by adding additional process steps to a standard CMOS process to implement a MEMS-based inductor achieves an efficiency below $60 \%$ at $10 \mathrm{MHz}$ and $75 \mathrm{~mW}$ output power [8].

This paper aims at demonstrating the feasibility of flipchipping a standard-CMOS active die on top of a siliconbased passive-integration die for realizing an integrated DC-DC down converter. Since processing the passive die involves significantly fewer masks than processing a nmCMOS active die, placing the relatively area-consuming passive components on a separate die makes sense from a low-cost point-of-view. The realized $\mathrm{SiP}$ aims at output powers in the $100-\mathrm{mW}$ range and fits inside a standard QFP64 package.

Section II highlights the main design aspects of the integrated converter, including design of the active die and determination of the needed passive-component values. Section III gives more details on the used passiveintegration process and the design of the passive die, particularly on the design of the LC output filter, and the complete SiP. The main measurement results are summarized in section IV. Finally, conclusions are drawn in section $\mathrm{V}$.

\section{DESIGN ASPECTS OF THE INTEGRATED DC-DC DOWN CONVERTER}

As described in section I, the use of a low-inductance integrated inductor necessitates a high switching frequency, which leads to increased switching losses without proper measures. Therefore, capacitive switching losses should be minimized using ZVS measures. In a buck converter with synchronous rectification, as considered in this paper, ZVS can be achieved by proper control of the power switches and by allowing the inductor current to go negative. This is explained with reference to the general block diagram of a synchronous buck converter with corresponding waveforms as shown in Fig. 1 .
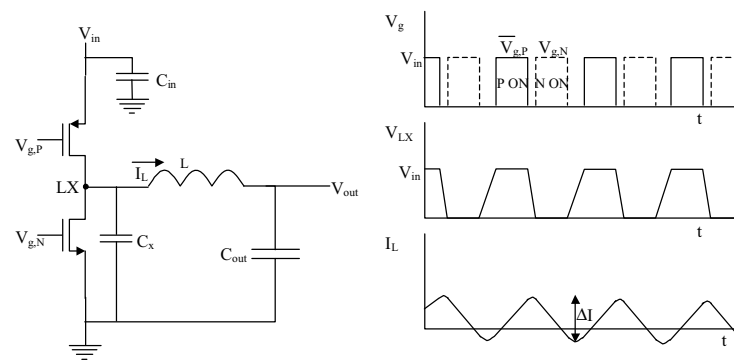

Figure 1. General block diagram of a synchronous DC-DC down converter with corresponding waveforms

When the PMOST is on (inverse of $\mathrm{V}_{\mathrm{G}, \mathrm{P}}$ equal to $\mathrm{V}_{\text {in }}$ in Fig. 1), the inductor current $\mathrm{I}_{\mathrm{L}}$ ramps up linearly. At the moment the PMOST switches off, the positive inductor current discharges the parasitic switch capacitance $C_{x}$ at the switching LX node between the two power MOSTs. With proper control of the dead time between switching off the PMOST and switching on the NMOST, the NMOST can be switched on when the drain-source voltage is zero. The capacitive losses are now reduced, since $C_{x}$ has been discharged by the inductor current $I_{L}$. When the NMOST is on $\left(\mathrm{V}_{\mathrm{G}, \mathrm{N}}\right.$ equal to $\left.\mathrm{V}_{\text {in }}\right)$, current $\mathrm{I}_{\mathrm{L}}$ ramps down linearly. When the current ripple $\Delta \mathrm{I}$ is large enough, current through the NMOST will reverse and $\mathrm{I}_{\mathrm{L}}$ will go negative. At the moment the NMOST switches off, $\mathrm{I}_{\mathrm{L}}$ will now charge $\mathrm{C}_{\mathrm{x}}$. With proper dead-time control the PMOST can now be switched on when the drain-source voltage is zero, again reducing capacitive losses. Note that the transition times at the LX node depend on $\mathrm{I}_{\mathrm{L}}$ and therefore on the load current. Therefore, in order to prevent that the MOSTs are switched on too early, leading to remaining capacitive switching losses, or too late, leading to parasitic body-diode losses, the dead-time control needs to be adaptive for optimum efficiency.

Various examples of adaptive dead-time control to reduce capacitive switching losses in high-switchingfrequency synchronous DC-DC down converters can be found in literature [9],[10],[11]. The ZVS DC-DC down converter in [9] with an input voltage $\mathrm{V}_{\text {in }}$ of $40 \mathrm{~V}$ applies a constant-off-time controller, where the frequency is varied to modulate the duty cycle. This leads to a constant value of the current ripple $\Delta \mathrm{I}$ large enough to ensure inductorcurrent reversal, since it is proportional to $\mathrm{V}_{\text {out }} \mathrm{T}_{\text {off. }} \mathrm{A}$ Delay-Locked-Loop (DLL) is used to ensure that the drain-source voltage $\mathrm{V}_{\mathrm{ds}}$ crossing zero and the gate-source voltage $V_{g s}$ passing the threshold voltage $V_{t}$ occur at the same moment. The ZVS DC-DC down converter described in [10],[11] with $\mathrm{V}_{\text {in }}=2 \mathrm{~V}$ is used for VoltageRegulator Module (VRM) applications. An additional capacitor is added in parallel to $\mathrm{C}_{\mathrm{x}}$ to increase the highlow and low-high transition times at the LX node. This enables more precise adaptive dead-time control, since delays in e.g. comparators in the control loop and gate drivers become less influential. As in [9], $\mathrm{V}_{\mathrm{ds}}$ zerocrossing and $\mathrm{V}_{\mathrm{gs}} \mathrm{V}_{\mathrm{t}}$-crossing comparators are used, the outputs of which are fed to an analog DLL.

The integrated DC-DC down converter described in this paper has a relatively low input voltage of $1.8 \mathrm{~V}$. Moreover, its output power is relatively low, leading to relatively small power switches and therefore relatively small parasitic LX-node capacitance $\mathrm{C}_{\mathrm{x}}$. The losses $\mathrm{f}_{\mathrm{s}} \mathrm{C}_{\mathrm{x}} \mathrm{V}_{\text {in }}{ }^{2}$ at a switching frequency $\mathrm{f}_{\mathrm{s}}$ of e.g. $50 \mathrm{MHz}$ are 


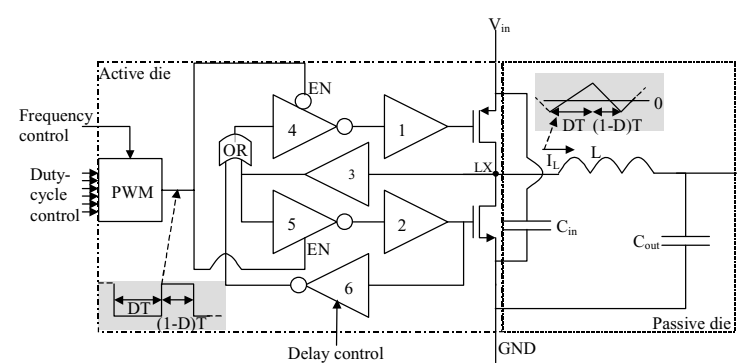

Figure 2. Block diagram of the integrated inductive DC-DC down converter

therefore in the same order as the power consumption of the adaptive dead-time controller reported in [11]. We therefore chose to implement a simpler ZVS scheme that may not be perfect, but also hardly consumes any additional power.

A block diagram of the implemented DC-DC down converter including the main components on the active and passive die is shown in Fig. 2. The active die contains the power stage, consisting of a PMOST and NMOST with corresponding drivers 1 and 2 , digital circuitry to implement a simple form of ZVS for the reduction of capacitive switching losses and a Pulse-Width Modulation (PWM) generator. No closed-loop control has been implemented yet, because we chose to focus on the technological aspects of the construction of a two-die SiP DC-DC converter, keeping the active-die design as simple as possible. This implies that the desired $\mathrm{V}_{\text {out }}$ is obtained by setting the correct duty cycle $\mathrm{D}$ via a 6-bit digital input code externally. The frequency of the PWM generator is controlled externally as well. The passive die includes the decoupling capacitor $\mathrm{C}_{\mathrm{in}}$, inductor $\mathrm{L}$ and output capacitor $\mathrm{C}_{\text {out }}$.

The ZVS operation of the power stage is achieved by monitoring the voltage at the LX node, see Fig. 2. First, consider switching off the PMOST at the end of the period DT. As soon as the PMOST has been switched off, the coil current $\mathrm{I}_{\mathrm{L}}$ will discharge the $\mathrm{LX}$ node, leading to a rapid decrease in voltage. Buffer 3 will pass this falling edge on to the input of inverter 5 , which is enabled by the PWM signal going 'high' at the start of period (1-D)T. As a result, the logic 'high' signal is passed on to driver 2, switching on the NMOST. The NMOST is switched off at the end of period (1-D)T by disabling inverter 5 . When coil current $\mathrm{I}_{\mathrm{L}}$ is negative (into the LX node), the LX-node voltage will increase. This is again detected by buffer 3 , which passes the rising edge on to the input of inverter 4 via an OR port. Inverter 4 is enabled by the PWM signal going 'low' at the start of period DT. Now, the logic 'low' signal is passed on to driver 1, switching on the PMOST. For high load currents, $\mathrm{I}_{\mathrm{L}}$ will no longer become negative. Therefore, an alternative path is needed to turn on the PMOST. When the gate of the NMOST goes 'low', the output of inverter 6 goes 'high' after a programmable delay. This signal is passed on in parallel to the LX-node signal path and will enforce the PMOST to switch on, even if the LX voltage is still low. This prevents a deadlock situation, but should be avoided in nominal cases.

Sizing of the MOSTs in the power stage has been optimized by minimizing combined switching and resistive losses for a switching frequency of $50 \mathrm{MHz}$, an output current of $100 \mathrm{~mA}$, and an inductance value of 20 $\mathrm{nH}$. The PMOST was sized roughly a factor 3 larger than the NMOST to compensate for the mobility difference of holes and electrons. Based on the sizes of the power MOSTs, the driver circuits have been optimized for optimum efficiency [12]. The PMOST driver uses 4 stages and a tapering factor of 3.3, whereas the NMOST driver uses two stages and a tapering factor of 4.5. The active die was realized in standard 5-metal-layer 0.18- $\mu \mathrm{m}$ CMOS.

The chosen inductance value is a trade-off between occupied area and total efficiency. Given the inductance value of $20 \mathrm{nH}$, the output capacitor value was chosen to be $75 \mathrm{nF}$ to obtain a maximum peak-to-peak voltage ripple at $50 \%$ duty cycle of $15 \mathrm{mV}$, excluding the influence of equivalent series inductance (ESL) and resistance (ESR) of the output capacitor. More information on the design of the LC output filter will be given in the next section. Since the switching frequency is relatively high, proper decoupling of the power stage is critical and particularly the series inductance in the connections of $\mathrm{C}_{\text {in }}$ should be very low. As will be described in the next section, the value of the decoupling capacitance was chosen as large as possible.

\section{Passive-InTEgration Process, Passive-Die DESIGN AND SiP CONSTRUCTION}

The proprietary Passive-Integration Connective Substrate (PICS ${ }^{\mathrm{TM}}$ ) process is silicon-based and provides a platform for the integration of resistors, capacitors and inductors [13],[14],[15]. It offers interesting advantages for realizing integrated DC-DC converters. First, it achieves large capacitance densities by utilizing trenchMOS capacitors. The PICS version used in this work achieves a density of $80 \mathrm{nF} / \mathrm{mm}^{2}$ [15]. Secondly, an $8-\mu \mathrm{m}$ thick copper top-metal layer available in this PICS version in addition to the first aluminum metal layer enables the design of spiral air-core inductors with reasonable performance. Fig. 3 illustrates the trench-MOS capacitor used to realize $\mathrm{C}_{\text {in }}$ and $\mathrm{C}_{\text {out }}$ as well a cross-sectional SEM image of the capacitor structure.

In order to form the high-density capacitors, pores of roughly $1 \mu \mathrm{m}$ width and $30 \mu \mathrm{m}$ depth are dry-etched in a high-resistivity $(1-5 \mathrm{k} \Omega \mathrm{cm})$ silicon substrate. The bottom electrode of the MOS capacitor structure in Fig. 3 is formed by making the pore walls of the structure highly conductive ( $\mathrm{n}^{+}$-doped bottom electrode). The dielectric is formed by an ONO (Oxide-Nitride-Oxide) layer. The thickness of $30 \mathrm{~nm}$ shown in Fig. $3 \mathrm{~b}$ corresponds to a capacitance density of $30 \mathrm{nF} / \mathrm{mm}^{2}$. The top electrode is formed by filling the pores with n-type in-situ-doped poly silicon. The top and bottom electrodes are then contacted with first-metal-layer aluminum. The achieved breakdown voltage at $80 \mathrm{nF} / \mathrm{mm}^{2}$ capacitance density is $15.5 \mathrm{~V}$, which

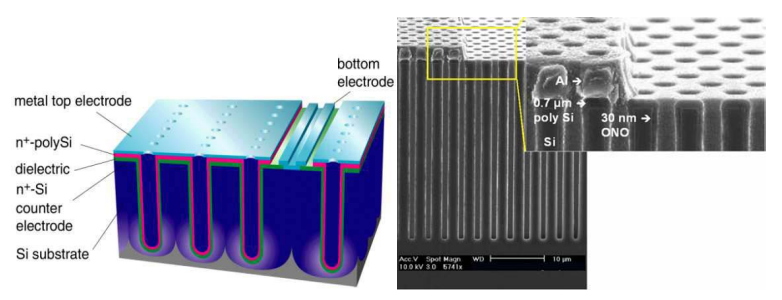

(a)

(b)

Figure 3. (a) Schematic representation of the trench-MOS capacitor, (b) Cross-sectional SEM image of a complete trench-MOS capacitor structure in dry-etched silicon [13] 


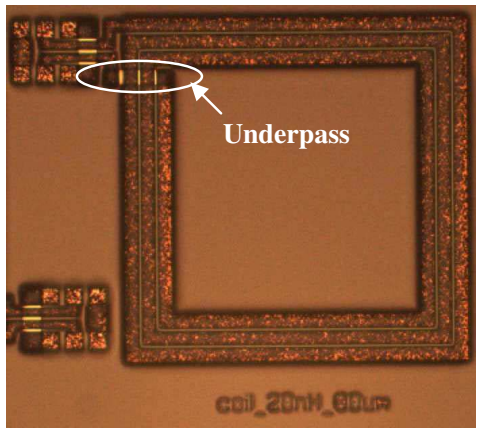

Figure 4. Photograph of the realized 20-nH planar air-core inductor in a separately laid-out version for wafer-level testing without the capacitor in the middle

is sufficient for use in the low-voltage DC-DC converters as considered in this paper.

In a space-saving layout, the output capacitor $\mathrm{C}_{\text {out }}$ has been realized inside the $20-\mathrm{nH}$ inductor. Since the output capacitance needed to be $75 \mathrm{nF}, \mathrm{C}_{\text {out }}$ occupied a surface area of $1.3 \times 1.3 \mathrm{~mm}^{2}$ to allow for some overhead for routing the connections to the capacitor electrodes. Since a square planar inductor type was chosen for simplicity of design, this implied that the inner dimension of the inductor needed to be $1.3 \mathrm{~mm} \times 1.3 \mathrm{~mm}$ as a boundary condition. A basic mathematical model for planar air coils was used to calculate first-order inductor dimensions that were later optimized using electro-magnetic Momentum ${ }^{\mathrm{TM}}$ simulations. This led to an inductor design with 3 turns with $80-\mu \mathrm{m}$ wide copper tracks spaced $8 \mu \mathrm{m}$ apart, i.e. the minimum possible distance between two copper tracks. This led to a total area of the LC filter of $1.8 \mathrm{~mm} \mathrm{x} 1.8$ $\mathrm{mm}$. The track width of the inductor was chosen as a compromise between parasitic series resistance and area, where the latter was restricted by the available package. The parasitic series resistance is also highly influenced by the length of the aluminum underpass used to contact the inner part of the winding. Moreover, the total area between the copper tracks forming the inductor and the aluminum underpass also determines the resonance frequency of the inductor, which should be significantly higher than the switching frequency. This also led to an optimization constraint, where the resonance frequency was chosen to be roughly $1 \mathrm{GHz}$. A photograph of a realized 20-nH planar air-core inductor without the capacitor in the middle is shown in Fig. 4. The differential Ground-Signal-Ground (GSG) probe pads for wafer testing of this inductor are shown top left. The position of the underpass has been indicated as well.

Very thin metal fingers have been used to alternately connect to the top and bottom electrodes of $\mathrm{C}_{\text {out }}$ to reduce eddy-current losses. This also led to splitting the capacitor up in many small-valued parallel capacitors. The copper top metal layer was used for routing for further reduction of the ESR and ESL of the capacitor. Since the bottom electrode of the capacitor had to be connected to the ground node of the DC-DC converter, the connection to this electrode also had to be routed to the outside of the inductor using an underpass. Various thin aluminum tracks were used in parallel here. The optimization criterion in this case was to balance the ESR of the capacitor, which increases with smaller track widths and/or less tracks in parallel, with the inductor resonance

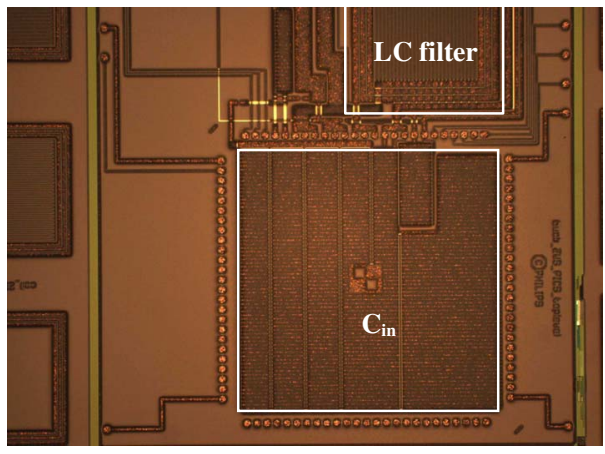

Figure 5. Photograph of the passive-die design

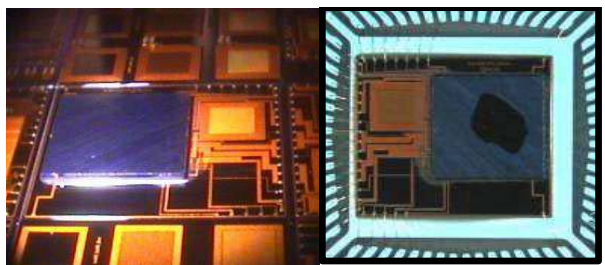

(a)

(b)

Figure 6. (a) CMOS die flip-chipped on PICS wafer before dicing, (b) CMOS/PICS sandwich placed in QFP64 package

frequency that decreases with larger tracks widths and/or more tracks in parallel. Finally, capacitor $\mathrm{C}_{\text {in }}$ was designed in a similar way as $\mathrm{C}_{\text {out }}$, using many small capacitors in parallel. Filling the complete available space underneath the active die with this capacitor maximized its value to roughly $300 \mathrm{nF}$. A photograph of the passivedie design is shown in Fig. 5. The bumping area for flipchipping the active die is shown at the bottom, including decoupling capacitor $\mathrm{C}_{\mathrm{in}}$. The LC filter with output capacitor $\mathrm{C}_{\text {out }}$ in the middle can be partly seen at the top of Fig. 5.

The complete $\mathrm{SiP}$ was formed by flip-chipping the $0.18-\mu \mathrm{m}$ CMOS active die facedown on the passive die using gold stud bumps and thermo compression. To reduce the impedance between the power-stage supply and ground connections on the active die and the decoupling capacitor and LC filter on the passive die three bumps were used in parallel for both the $V_{\text {in }}$ and GND connections. After placing the active dies on the passive wafer, the passive wafer was diced and the resulting sandwiches of active-die-on-passive-die were bonded in standard QFP64 packages. Photographs of the flipped active die on top of the passive wafer before dicing and the diced CMOS/PICS sandwich inside the QFP64 package are shown in Fig. 6.

\section{MEASUREMENT RESULTS}

The LC filter has also been laid out separately elsewhere on the PICS wafer to investigate the impact of placing $\mathrm{C}_{\mathrm{out}}$ inside the inductor. GSG probe pads and proper de-embedding structures were added to allow proper on-wafer characterization of the structures. The full impact of placing the capacitor in the middle of the inductor could not be predicted during design, since electro-magnetic simulation of the complete 3D capacitor structure was not possible with Momentum ${ }^{\mathrm{TM}}$. Only the impact of the thin metal connections to the capacitor could be taken into account. Fig. 7 shows the measured 


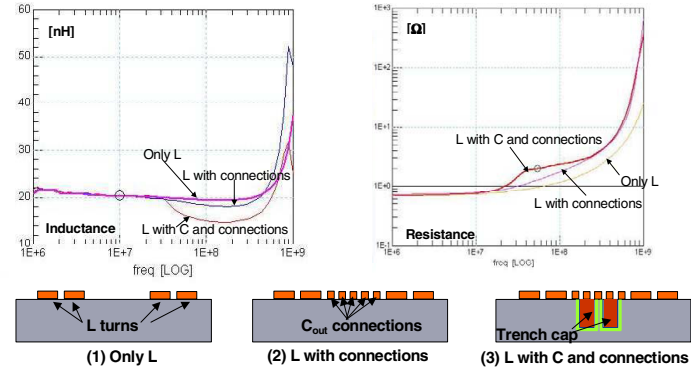

Figure 7. Measured inductance and resistance as a function of frequency for three inductor variants: (1) only L, (2) L with connections, (3) $\mathrm{L}$ with $\mathrm{C}$ and connections

inductance and resistance of the inductor as a function of frequency for three cases: an inductor with nothing inside (1, see Fig. 4 for a close-up photograph), an inductor with only the capacitor connections inside (2) and an inductor with the complete connected capacitor inside (3, also used in complete passive-die design in Fig. 5), see Fig. 7. The inductance decreases to roughly $16 \mathrm{nH}$ at $50 \mathrm{MHz}$ and the resistance increases to roughly $2 \Omega$ at $50 \mathrm{MHz}$ when the trench capacitor is added (case 3 in Fig. 7). Apparently, eddy-current losses in the diffusions in the capacitor are dominant. This will of course have a negative impact on the efficiency reported below. Resonance of the inductor indeed occurs at roughly $1 \mathrm{GHz}$.

The measured efficiency for various switching frequencies as a function of output current for an input voltage $\mathrm{V}_{\text {in }}$ of $1.8 \mathrm{~V}$ and fixed duty cycles of $62.4 \%$ and $42 \%$ are shown in Fig. 8 and Fig. 9, respectively. The same low delay was used for the inverter 6 at all switching frequencies, see Fig. 2. This implies that the maximum dead time between the PMOST switching on and the NMOST switching off equals this externally programmed delay, see Fig. 2.

In both Fig. 8 and Fig. 9, a higher efficiency is achieved for a higher switching frequency at low output currents. This suggests that ohmic losses due to the relatively large current ripple are dominant here. Apparently, these ripple losses are lower for higher switching frequency, implying that decreased ripple current has more impact than increased inductor resistance. For increasing output current the efficiency then increases due to larger output power. For higher switching frequencies the efficiency curve levels off earlier than expected. This is caused by the fact that the inductor current $\mathrm{I}_{\mathrm{L}}$ is no longer negative, such that the PMOST is switched on after the externally

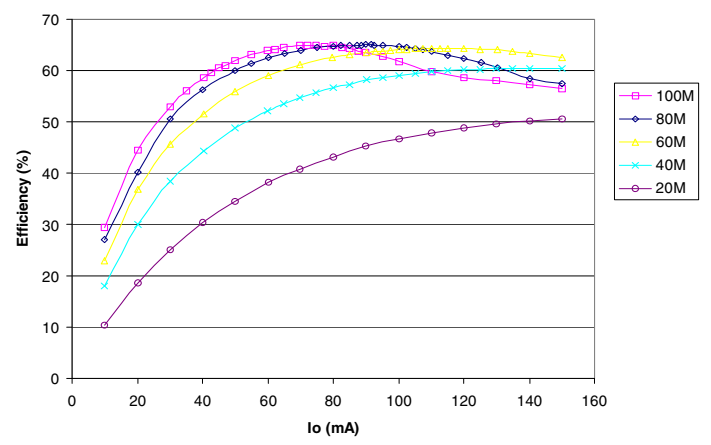

Figure 8. Measured efficiency as a function of output current for various switching frequencies $(\mathrm{D}=62.4 \%)$

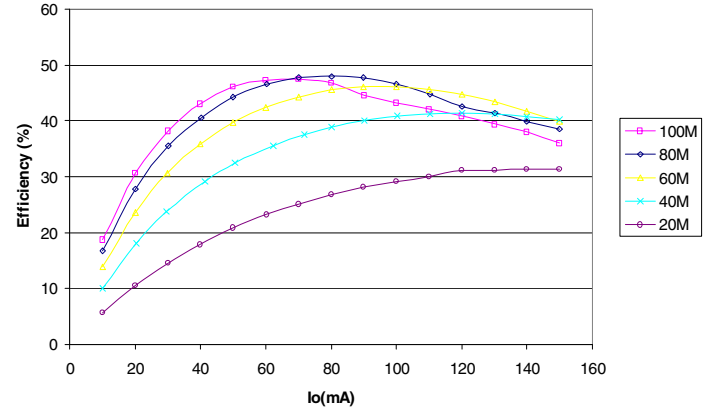

Figure 9. Measured efficiency as a function of output current for various switching frequencies $(\mathrm{D}=42 \%)$

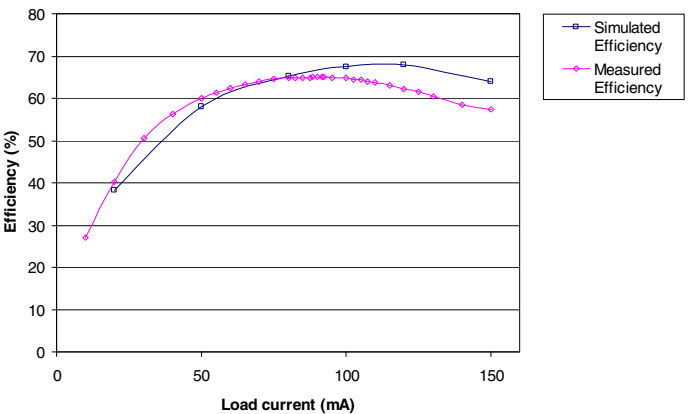

Figure 10. Comparison between simulated and measured efficiency as a function of output current for a switching frequency of $80 \mathrm{MHz}$ and duty cycle of $62.4 \%$

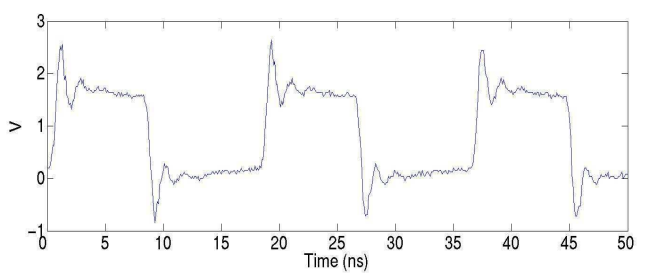

Figure 11. Measured LX-node voltage at a switching frequency of $50 \mathrm{MHz}$ and output current of $15 \mathrm{~mA}$

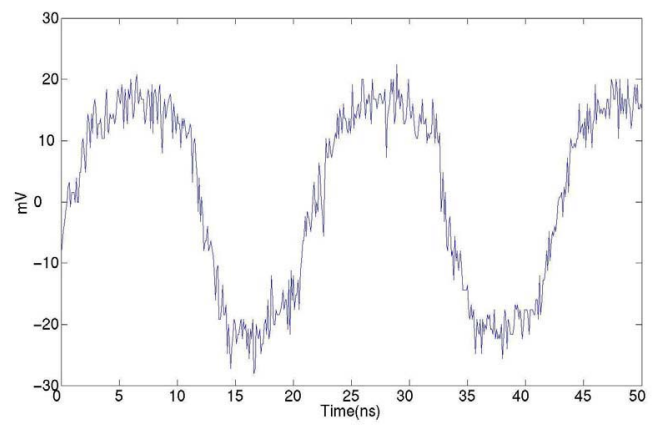

Figure 12. Measured output-voltage ripple at a switching frequency of $50 \mathrm{MHz}$ and output current of $15 \mathrm{~mA}$

controlled delay only. Body-diode conduction losses of the NMOST decrease the efficiency in this case. The higher the switching frequency, the lower the output current for which $\mathrm{I}_{\mathrm{L}}$ is no longer negative (smaller ripple current $\Delta \mathrm{I}$ ) and the more impact the programmed delay has on the efficiency. In fact, the ZVS implementation was optimized for use around $50 \mathrm{MHz}$, where the efficiency is increased by a few percent compared to hard switching and where the alternative path is not used, see Fig. 2. Still, the maximum efficiency for $D=62.4 \%$ 
$\left(\mathrm{V}_{\text {out }}=1.1 \mathrm{~V}\right)$ is $65 \%$, which is higher than a linear regulator would have for the same voltage conditions. The decrease of efficiency at larger output currents is caused by increased ohmic losses in combination with a lower increase in output power than anticipated. This latter aspect is caused by the absence of a control loop, which would vary the duty cycle such that $\mathrm{V}_{\text {out }}$ would remain constant at higher output current. The peak efficiencies at $\mathrm{D}=42 \%$ in Fig. 9 are lower at roughly $48 \%$, compared to the peak efficiencies of $65 \%$ at $\mathrm{D}=62.4 \%$ in Fig. 8 . This is caused by the lower output power at the same output current, since $\mathrm{V}_{\text {out }}$ is lower due to the lower duty cycle.

Fig. 10 shows a comparison between simulated and measured efficiency at a switching frequency of $80 \mathrm{MHz}$ and a duty cycle of $\mathrm{D}=62.4 \%$. An equivalent-circuit model was used for the inductor, which was fitted to the measurement results of ' $\mathrm{L}$ with $\mathrm{C}$ and connections' in Fig. 7. The simulations in Fig. 10 revealed that the main cause for the relatively low peak efficiency is the total ohmic resistance in the current path, which leads to substantial losses due to the relatively high ripple current $\Delta \mathrm{I}$ to enable ZVS operation. Ohmic losses can be substantially reduced by moving $\mathrm{C}_{\text {out }}$ outside the inductor and by decreasing the on-chip connection resistance to the power switches. This would improve efficiency.

Fig. 11 shows the measured voltage at the LX node at a switching frequency of $50 \mathrm{MHz}$ and an output current of $15 \mathrm{~mA}$. The observed ringing in the LX-node voltage was caused by the measurement probe. No internal supply ringing was observed using additional sense wires to sense the internal supply voltages. This illustrates the effectiveness of the decoupling of the power stage. Due to the relatively low output current, the LX-node voltage indeed becomes positive at the end of the conduction period of the NMOST. This implies that the inductor current has reversed and that the ZVS scheme is functional in this case. Moreover, no body-diode losses can be observed from Fig. 11.

The output ripple voltage of the integrated DC-DC down converter for the same conditions as valid in Fig. 11 is shown in Fig. 12. The peak-to-peak ripple voltage is 35 $\mathrm{mV}$, which is roughly a factor of two higher than the value of $15 \mathrm{mV}$ for an ideal output capacitor described in section II. This is partly caused by the fact that the inductance is only $16 \mathrm{nH}$ at $50 \mathrm{MHz}$. Another reason is that non-idealities in the output capacitor will increase the ripple voltage.

The realized integrated DC-DC down converter has a maximum input voltage of $1.8 \mathrm{~V}$ due to the used $0.18-\mu \mathrm{m}$ CMOS process. Enabling Li-ion-battery input voltages by applying layout tricks in standard CMOS would enable a more favorable comparison between integrated DC-DC converters and linear regulators [16]. Since higher switching voltages would be used in this case, this would also be a better test case for implementation of ZVS measures.

\section{CONCLUSIONS}

An integrated inductive DC-DC down converter has been realized by flip-chipping a $0.18-\mu \mathrm{m}$ CMOS active die containing the power stage, drivers and PWM signal generator on a passive-integration die containing the input decoupling capacitor and the output LC filter. The passive-integration process is based on trench-MOS capacitors and achieves an $80-\mathrm{nF} / \mathrm{mm}^{2}$ capacitance density. An $8-\mu \mathrm{m}$ thick copper top metal layer enables the integration of planar air-core inductors. The realized SiP does not need any external components and achieves a maximum efficiency of $65 \%$ at a switching frequency of $80 \mathrm{MHz}$, an input voltage of $1.8 \mathrm{~V}$, an output voltage of $1.1 \mathrm{~V}$ and an output current of $100 \mathrm{~mA}$. Future steps include optimizing the LC filter by moving the output capacitor outside the inductor, decreasing the connection resistances of the power switches and allowing direct $\mathrm{Li}$ ion battery connection using layout tricks to implement high-voltage power switches in nm-CMOS. Application of integrated inductive DC-DC down converters is envisioned for enabling system integration of power management.

\section{ACKNOWLEDGMENT}

The authors would like to thank Malal Bathily, Stefan Menten, Derk Reefman and Jerome Saby for performing the active-die design, Lionel Guiraud, Eric Pieraerts and Sophie Ledain for assistance in realizing the passive-die design and Dick Mapanao for assembly of the complete System-in-Package. Ralf Pijper and Luuk Tiemeijer are acknowledged for performing the wafer-level LC-filter characterization measurements. Fred Roozeboom and Patrick Smeets are acknowledged for useful comments on the original manuscript.

\section{REFERENCES}

[1] M. Meijer, J. Pineda de Gyvez, R. Otten, 'On-chip digital power supply control for system-on-chip applications', Proc. IEEE International Symposium on Low-Power Electronics and Design, ISPLED’05, pp. 311-314, August 8-10, 2005

[2] B. Arntzen, D. Maksimovic, 'Switched-Capacitor DC/DC Converters with Resonant Gate Drive', IEEE Trans. Power Electron., vol. 13, no. 5, pp. 892-902, September 1998

[3] M. Makowski, D. Maksimovic, 'Performance Limits of SwitchedCapacitor DC-DC Converters', Proc. IEEE Power Electronics Specialists Conference, PESC'95, vol. 2, pp. 1215-1221, June 1822, 1995

[4] S. Bin, Y. Yujia, W. Ying, H. Zhilang, 'High Efficiency, Inductorless Step-Down DC/DC Converter', Proc. IEEE International Conference on ASIC, ASICON 2005, vol. 1, pp. 395-398, October 24-27, 2005

[5] G. Schrom, P. Hazucha, J. Hahn, D. Gardner, B. Bloechel, G. Dermer, S. Narendra, T. Karnik, V. De, 'A 480-MHz, Multi-Phase Interleaved Buck DC-DC Converter with Hysteretic Control', Proc. IEEE Power Electronics Specialists Conference, PESC'04, vol. 6, pp. 4702-4707, June 20-25, 2004

[6] G. Schrom, P. Hazucha, F. Paillet, D. Rennie, S. Moon, D. Gardner, T. Karnik, P. Sun, T. Nguyen, M. Hill, K. Radhakrishnan, T. Memioglu, 'A $100 \mathrm{MHz}$ Eight-Phase Buck Converter Delivering $12 \mathrm{~A}$ in $25 \mathrm{~mm}^{2}$ Using Air-Core Inductors', Proc. IEEE Applied Power Electronics Conference, APEC'07, pp. 727-730, February 25-March 1, 2007

[7] S. Abedinpour, B. Bakkaloglu, S. Kiaei, 'A $65 \mathrm{MHz}$ Switching Rate, Two-Stage Interleaved Synchronous Buck Converter with Fully Integrated Output Filter,' Proc. IEEE International Symposium on Circuits and Systems, ISCAS'06, pp. 5315-5318, May 21-24, 2006

[8] S. Musunuri, P. Chapman, 'Design of Low Power Monolithic DCDC Buck Converter with Integrated Inductor', Proc. IEEE Power Electronics Specialists Conference, PESC'05, pp. 1773-1779, June 12-16, 2005

[9] W. Lau, S. Sanders, 'An Integrated Controller for a HighFrequency Buck Converter', Proc. IEEE Power Electronics Specialists Conference, PESC'97, pp. 246-254, June 22-27, 1997

[10] S. Chen, O. Trescases, W. Tung Ng, 'Fast Dead-Time Locked Loops for a High-Efficiency Microprocessor-Load ZVS-QSW DC/DC Converter', Proc. IEEE Conference on Electron Devices 
and Solid-State Circuits, EDSSC'03, pp. 391-394, December 1618,2003

[11] O. Trescases, W. Tung Ng, S. Chen, 'Precision Gate Drive Timing in a Zero-Voltage-Switching DC-DC Converter', Proc. IEEE Symposium on Power Semiconductor Devices and ICs, ISPSD’04, pp. 55-58, May 24-27, 2004

[12] G. Villar, E. Alarcon, J. Madrenas, F. Guinjoan, A. Poveda, 'Energy Optimization of Tapered Buffers for CMOS On-Chip Power Converters', Proc. IEEE International Symposium on Circuits and Systems, ISCAS'05, Vol. 5, pp. 4453-4456, May 2326, 2005

[13] F. Roozeboom, A. Kemmeren, J. Verhoeven, F. van den Heuvel, J. Klootwijk, H. Kretschman, T. Frič, E. van Grunsven, S. Bardy, C. Bunel, D. Chevrie, F. le Cornec, S. Ledain, F. Murray, P. Philippe, 'More than 'Moore': towards Passive and System-in-Package integration', Proc. of Electrochem. Soc. Symp., vol. 2005-8, pp. $16-31,2005$
[14] F. Roozeboom, A. Kemmeren, J. Verhoeven, F. van den Heuvel, J. Klootwijk, H. Kretschman, T. Frič, E. van Grunsven, S. Bardy, C. Bunel, D. Chevrie, F. le Cornec, S. Ledain, F. Murray, P. Philippe, 'Passive and heterogeneous integration towards a silicon-based System-in-Package concept', Thin Solid Films, vol. 504, pp. 391396, 2006

[15] F. Roozeboom, J. Klootwijk, J. Verhoeven, F. van den Heuvel, W. Dekkers, S. Heil, J. van Hemmen, M. van de Sanden, W. Kessels, F. le Cornec, L. Guiraud, D. Chevrie, C. Bunel, F. Murray, H. Kim, D. Blin, 'ALD options for Si-integrated ultrahigh-density decoupling capacitors in pore and trench designs ', Electrochem. Soc. Trans., Vol. 3, No. 15, pp. 173-181, 2007

[16] A. Heringa, J. Sonsky, 'Novel power transistor design for a process independent high voltage option in standard CMOS', Proc. IEEE Symposium on Power Semiconductor Devices and IC's, ISPSD'06, pp. 1-4, June 4-8, 2006 